Article

\title{
Air to Water Generator Integrated Systems: The Proposal of a Global Evaluation Index-GEI Formulation and Application Examples
}

\author{
Lucia Cattani ${ }^{1, *(1)}$, Paolo Cattani ${ }^{2}$ and Anna Magrini ${ }^{3}$ (i) \\ 1 SEAS SA, Société de l’Eau Aérienne Suisse, Technical Office, Via dell'Industria 13/A, \\ 6826 Riva San Vitale, Switzerland \\ 2 Freelancer Engineer and Developer, Via Piermarini 4/L, 26900 Lodi, Italy; mail@paolocattani.com \\ 3 Department of Civil Engineering and Architecture, University of Pavia, 27100 Pavia, Italy; magrini@unipv.it \\ * Correspondence: lucia.cattani@tiscali.it
}

Citation: Cattani, L.; Cattani, P.; Magrini, A. Air to Water Generator Integrated Systems: The Proposal of a Global Evaluation Index-GEI Formulation and Application Examples. Energies 2021, 14, 8528. https://doi.org/10.3390/en14248528

Academic Editor:

Alfredo Guardo Zabaleta

Received: 21 October 2021

Accepted: 8 December 2021

Published: 17 December 2021

Publisher's Note: MDPI stays neutral with regard to jurisdictional claims in published maps and institutional affiliations.

Copyright: (c) 2021 by the authors. Licensee MDPI, Basel, Switzerland. This article is an open access article distributed under the terms and conditions of the Creative Commons Attribution (CC BY) license (https:// creativecommons.org/licenses/by/ $4.0 /)$.

\begin{abstract}
Due to water scarcity, in the last few decades, air-to-water generator (AWG) technology, whose useful effect is the extraction of water from air, has been improved. In particular, in the last few years, advanced AWG integrated systems have been developed. Such systems permit, not only to condense water from air, but also the smart use of the by-side effects of the process in order to partially or totally cover the heating ventilation air conditioning (HVAC) needs of a building. Presently, there are no evaluation tools that permit a complete comparison among AWG machines, taking into account all the useful effects that can be obtained at the same time and with the same energy input. The current work, starting from the need for such a tool, proposes a global index whose formulation considers all useful effects of an integrated system, the energy required to obtain them, and the integration degree of the machine. The index translates into a single number the system global efficiency, by means of a particular combination of existing efficiency indicators. In its extended formulation, it can be applied, not only to AWGs, but also to other HVAC integrated systems, as well as to combinations of non-integrated and integrated solutions. In addition to equations, the paper provides calculation examples and a case study in order to show the practical application and advantages of GEI.
\end{abstract}

Keywords: atmospheric water condensation; air-to-water technology; water extraction efficiency; energy efficiency ratio; coefficient of performance; water energy transformation; refrigeration

\section{Introduction}

Scarcity, lack of safety, and pollution related to water are global issues that affect about one-third of the world's population, as estimated by the World Health Organization (WHO) in [1]. Traditional water sources are facing depletion and pollution, as stated in the United Nations World Water Development Report 20 [2], and in the Climate Change and Land special report by the Intergovernmental Panel on Climate Change (IPCC) [3]. In addition to better water management, accessible new fresh water sources are also needed. Thus, lately, air-to-water generator (AWG) technology research has been advancing quickly [4] as these systems permit to extract water vapour from the air, which can be considered as an alternative water source.

The most diffused AWG systems are based on a compression reverse cycle and their main issue is energy consumption, as underlined in [4]. In order to address such an issue, and provide water from air with an acceptable energy consumption, in the last few years, advanced models of compression reverse cycle AWGs have been developed, implementing the integrated systems approach. This approach consists in designing systems and/or plants that are able to provide more than one useful effect at the same time while using the same energy input. In such a way, it would be possible to exploit energy in the best way, minimizing or reusing waste products, thus minimizing energy consumption [5]. 
The advantages given by an integrated system and an integrated design approach do not only consist in higher efficiency in the energy use, but also in the minimization in the use of raw materials. In fact, for example, if two useful effects can be achieved by the same machine, there will be one less machine to be built. Smart cities [6], and in particular smart buildings, are strongly based on this idea of integration [7]. At the city scale, one of the most diffused and prominent examples of such an approach is thermoelectric generation coupled with district heating. One can remember, for example, the "Dava" plant in Sweden, which provides the city of Umea with $170 \mathrm{MW}$ of power (about 30\% of it is electricity) [8], or the "Silla 2" plant in Milan, which in 2019 produced 380 GWh of electrical power and 449 GWh of thermal energy [9]. At the building scale, cogeneration [10] and/or trigeneration are well-known integrated solutions [11].

Advanced reverse cycle-based plants follow such an integrated approach as well. For example, innovative solutions in terms of air conditioning have been designed to cover domestic water heating by means of condensation heat [12]. Such a thermal energy is no longer disposed of in the environment as a waste product, but it is promoted to resource by means of control algorithms that are coupled with smart circuits and coils $[13,14]$.

As for AWG technology, a first design of an integrated system able to provide water and air conditioning can be found in [15], where the energy used for air conditioning permits the possibility of extracting water from air at the same time. A comparison with a traditional air-conditioning plant, with the same cooling effect, demonstrated that the water production, by means of the innovative plant, was almost cost free.

In [16], the term "integrated systems" was particularly applied to AWG machines designed to be easily integrated into buildings and that are able to exploit at least one of the other useful effects of a reverse cycle, in addition to water generation, in order to cover a part, or the entirety, of heating ventilation air conditioning (HVAC) needs. In the quoted research, an AWG-integrated system was designed and built to cover the entire drinking water needs of a hotel in Villahermosa, Mexico, as well as all the heating energy required by the domestic water. The system was also connectable to an existing air treatment unit (ATU) in order to help it with the fresh and dry air flux (averagely of $8500 \mathrm{~m}^{3} / \mathrm{h}$ ) coming from the evaporator. In this case, the innovative plant yielded a meaningful energy saving, in comparison to the existing system, while providing enough water. Savings were enough to repay the investment costs in about two-and-a-half years. This integration improvement was demonstrated by calculations based on the energy consumption measures obtained before and after the installation of the integrated AWG system.

The integrated approach is meant as a more efficient use of energy in comparison to traditional plants, but such an advantage needs to be made explicit, in particular during the design stage, when plant configurations must be chosen.

A common issue in integration is the complexity due to the various components involved in each system and their interactions. Determining if one solution is better than another is not a simple operation. One way to provide the first evaluation metric, recommended when complex systems, including many variables, are involved, is to formulate an index. However, to build an index requires deep research work, because such a tool must be simple, compact, readable, but, at the same time, effective and meaningful. One of the current research issues concerns the correct way to combine variables in order to obtain such a goal [17]. An index for evaluating the energy efficiency of integrated systems should be able to consider and weigh, not only the benefits/costs related to each useful effect, but also the advantages given by their integration.

Due to the novelty of the technology, presently, as underlined in [18], there is no index that is meaningful and able to give, in a compact and intuitive way, an indication on the efficiency of an integrated AWG machine, thus permitting a fast comparison with other plants, integrated or otherwise. Nowadays, for integrated AWG machines, the only way to carry out such a comparison is to use an analytic energy calculation of each individual useful effect provided by each system, such as heating, cooling, water extraction, etc. For a global evaluation of the system, the different efficiency values must be aggregated in 
some way. For example, in [15], the authors carried out a detailed performance calculation of a conventional air conditioning plant as well as that of an integrated machine, demonstrating, for the examined case, the effectiveness of the latter. It can be said that, the analytical calculations are suitable when, in a stated configuration, deep analysis of energy consumption is required, but it cannot be the mean during the design stage, when it is required to operate a choice among different possible configurations and to identify the most suitable plant that gives the best cost/benefit ratio. The need for an index is also clear from the perspective of future processes of standardization, where indicators and indices are a preferential support for standard definitions.

The aim of the current work is to provide, for the first time, an evaluation index, called the global evaluation index (GEI), tailored to integrated machines, simple to be applied, and able to translate the integration degree and the energy efficiency, related to each provided useful effect, into a single number. In other words, GEI is a simple metric to measure the advantages of integration, without losing physical meaning. In order to achieve such a goal, authors analysed the current trends in global energy efficiency evaluation. The GEI formulation was, thus, inspired by such current and diffused trends, aimed at developing indices on the basis of combinations of single indicators. Such an index is a novelty, in the literature and in practice, and it is an easy tool for carrying out immediate comparisons of different plant configurations.

In the next section, a brief literature overview is presented on the basis of the GEI formulation process.

\section{Literature Review}

As underlined in the previous section, integrated plants are one of the main trends in energy sustainability. Energy consumption, and thus, efficiency, is one of the most important elements to be taken into account in the comparison process of different plant solutions in the design stage. Nowadays, energy labels and/or well-known indicators, such as the coefficient of performance (COP) [19] and the energy efficiency ratio (EER) [20], are commonly used to provide at a glance the idea of reverse cycle machine efficiency, but both COP and EER were formulated in order to consider only one useful effect of such a cycle. As a matter of fact, COP represents the ratio between the heating effect and energy (or the power, if the numerator and denominator are given in power terms) required to obtain such an effect. In a similar way, EER is calculated taking into account, as the numerator, the cooling effect.

For AWG machines, the authors have proposed a dedicated indicator, water energy transformation (WET) [18], which provides a metric for energy efficiency related to the specific useful effect of an AWG system: the water production. There are basically two scopes of WET:

- To overcome issues related to the only other existing indicator for AWGs, specific energy consumption (SEC) [21]

- To provide a standard tool, based on the same structure as COP and EER, for water production efficiency calculation from an energy point of view.

In [22], a new solar atmospheric water harvesting integrated system, able to provide water and to cool down and dehumidify ambient air, was presented. Only SEC was used to compare the integrated system with a solar humidification-dehumidification distillation (HDD) system. SEC gives only the energy consumption per liter of produced water; therefore, its value was not representative of the real effectiveness of the integrated plant in comparison to HDD, as declared by those same authors, because the cooling effect was not taken into account.

It is intuitive that, in order to compare the effectiveness of different integrated solutions, all useful effects that such solutions can provide with the same energy consumption must be considered. This can be done, for example, by analyzing the above indicators, COP, EER, WET, or SEC, one by one, as carried out in [16], or as was done in [23], where a 
system for water recovery from an ATU was described and water and energy savings were considered, even if they were disjointed.

Nevertheless, referring to integrated systems, the comparison by means of those indicators, taken separately, can be difficult, as noted in [24].

The need to overcome such a difficulty, and to provide an intuitive and simple evaluation tool in order to permit easy comparison among different complex solutions, is the basis of index creation, and is strongly recommended by European community in an environmental context, for example [25]. The aim of an index is to combine all the different indicators involved in an analysis into a single value, which then synthesizes the information. The advantage of such an approach is to provide an easy metric that permits to carry out fast comparisons among complex systems. This approach is widely used, for example, in building energy performance evaluation, as described in [26]. Other recent examples can be found in [27], where a new index was developed in order to describe HVAC sustainability in terms of water use, and in [28] where another index was proposed to evaluate efficiency in the design stage of data centres, as related to the use of free cooling. All these indices are tools that help, through a comparatively simple calculation, in the choosing process among different solutions, which are sometimes apparently similar. As for AWGs, the only index that can be found is the moisture harvest index (MHI), which provides a tool to evaluate if environmental conditions are effective for AWGs, based on a compression reverse cycle [29]. Such an index does not take into account integrated AWGs, and it is not focused on integrated system comparisons.

Instead, for cogeneration and trigeneration plants, an index formulation is widely used. In particular it is possible, not only to find something that concerns primary energy savings, but also economic evaluations [30]. In particular, for integrated HVAC systems, in [14], a particular overall COP was calculated, given by a ratio between the sum of the useful effect powers divided by the power required to obtain them. Such an approach, also used in [30] for trigeneration systems and heat pumps, is an attempt to give one value for the efficiency of the whole system, but it can only be used in the comparison of homogenous systems. The approach is not energetically congruent when a comparison between integrated and non-integrated systems is carried out. This is because it does not take into account the integration aspect, as is in the following.

On the basis of the evident need for a parameter that can quantitatively and synthetically express the energetic advantages of AWG- and HVAC-integrated machines, the authors proceeded to formulate the global evaluation index (GEI). Such an index combines the main indicators of energy performance related to the useful effects provided by a machine, taking its integration level into account.

In order to describe the index and its use, the paper is organized as follows:

- A brief description of AWG-integrated machine technology;

- A summary of the WET indicator in order to facilitate an understanding of the genesis of the GEI index;

- The GEI index formulation, highlighting that such a formulation is suitable, not only for AWG-integrated machines, but also for HVAC-integrated machines;

- The extended version of GEI index formulation, suitable for the evaluation of combinations of integrated and non-integrated systems;

- A practical explanation of GEI formulation.

After that, the effectiveness of GEI as a compact comparison tool will be demonstrated. In particular it will be shown:

- by means of numerical examples, how GEI avoids the described issues of the overall $\mathrm{COP}$ and permits comparison among different systems by means of its single value;

- how to manage system powered by different energy sources, types and vectors, by means of primary energy will be described;

- a case study that takes an integrated AWG machine and other system combinations into account will be presented and discussed; 
- an example of application of GEI to heterogeneous combination of plants will be finally described (with different levels of integration).

\section{GEI Formulation}

The performance study of an AWG-integrated machine for water extraction from air was the starting point for the formulation of GEI. To understand both the need and the formulation process of the index, it is useful to remember why AWG systems were created and how an integrated AWG system works. Moreover, as the idea of GEI is based on a combination of performance parameters, including, when needed, the WET indicator that calculates water production efficiency (recently proposed by the authors), the WET formulation will be briefly summarized.

\subsection{Integrated AWG Systems}

In the last few years, studies and applications on water extraction from air have been rapidly increasing [21]. The physical principle of such an idea is to artificially achieve the dew point of a mass of atmospheric (humid) air in order to obtain its vapor content condensation. Fog nets that directly capture liquid water, represented by micro drops of fog, are the only exception to the AWGs current scenario for such a principle. This solution is not very widespread, because it can only be applied under particular weather conditions.

In addition to fog nets, presently, there are three main approaches to AWGs. The first one, most widespread because it can be easily sized to produce tens to thousands of liters of water per day [31], is based on a compression reverse cycle, employing electrical energy to work. Air is cooled under its dew point by means of such a cycle and the condensed water is collected. The second method employs desiccants, such as silica gel or a metal organic framework (MOF) [32], to capture the humidity of environmental air and release it by means of thermal energy into a closed volume of air in order to increase the dew point. Vapour condensation can then be obtained using less energy because the air is nearer to saturation conditions. In existing models, water production is on the order of few litres per day. The third method uses thermoelectric coolers (TEC) [33] to cool down the air under its dew point; also in this case, water production is a few litres per day.

One of the main issues of all these AWGs technologies is the energy consumption, which is intrinsically involved in moisture condensation and/or air moving. In addition to sensible heat that must be removed from air to achieve a dew point, which depends on environmental conditions, there is another thermal energy contribution that increases the energy consumption due to the phase change of water, from vapor into liquid. Such a phase change requires the removal of the latent heat of condensation. That energy, at the operating conditions of AWGs, can be averaged to be equal to $2460 \mathrm{~kJ}$ for each $\mathrm{kg}$ of condensed water [18]. Thus, it is clear that even if air is under saturation conditions (relative humidity equal to $100 \%$ ) then the thermal energy required to obtain only ten litres of water is in the mega-Joule order of magnitude. Another aspect of energy consumption is related to air movement. Vapor content in environmental air can vary from few grams up to some tens of grams per cubic meter, thus, in order to obtain few litres of water, some hundreds of cubic meters of air must be moved inside the AWG system. Normally such a movement is obtained through the use of electrical fans, whose consumption can reach some mega Joules for a production of one cubic meter of water, as can be easily deduced by the results in [16].

In order to lessen the energy consumption issue, various solutions have been developed, such as water harvesting by means of particular desiccants, based on metal organic framework (MOF) technology, combined with systems that use thermal energy from solar radiation, and the natural thermal gradient due to night and day cycle [34]. MOF-based solutions using green energy are presently employed for daily production of few litres because they require wide contact surfaces between air and the MOF. In [35], how to enhance water harvesting and minimize the energy consumption of a thermo-electric cooler (TEC)based AWG was studied. In this case, the first target was achieved with a hydrophobic 
cover of the cold surface, while the second one was obtained by means of cooling energy reuse, conveying the cooled air to the hot surface of the TEC.

Another way to bypass the energy issue in water extraction from air, as noted in [36], is represented by integrated AWG systems based on a compression reverse cycle. Those AWG machines, whose design is an evolution of AWGs based on the compression reverse cycle, can produce from tens to thousands litres per day with a comparatively low requirement of space: the biggest models have dimensions comparable to common chiller units with some hundred kilowatts of cooling power [37]. In a simple AWG machine, the reverse cycle is employed solely to cool environmental air below its dew point and obtain, with a certain energy consumption, condensation of part of the air humidity content. An integrated AWG system, instead, is designed to exploit more than one useful effect of such a reverse cycle, with the same energy consumption of a simple AWG machine.

In Figure 1, as an example of the integrated system approach, a possible AWG working scheme, based on the real application described in [16], is represented.

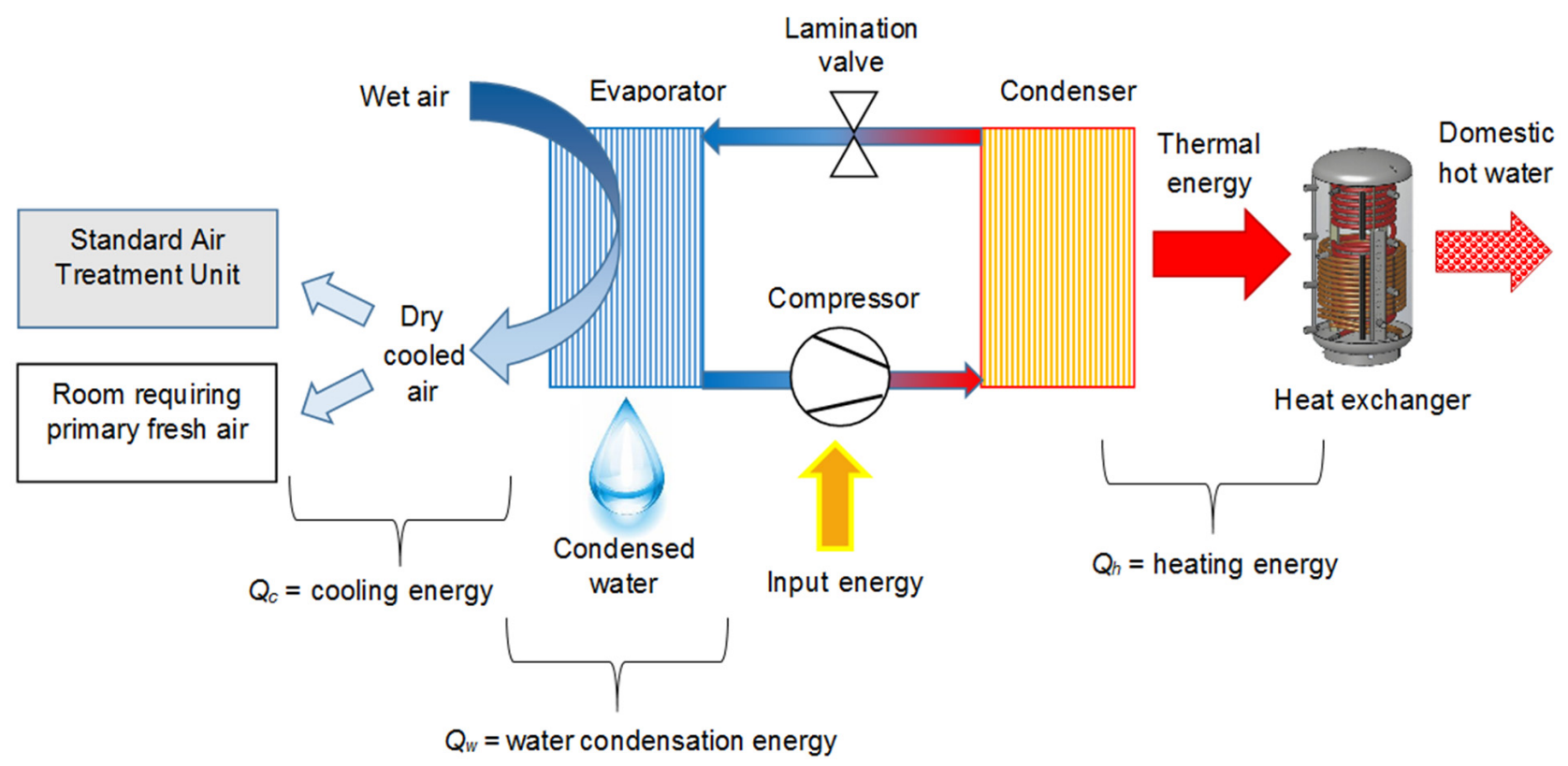

Figure 1. Example of an AWG integrated system scheme.

In this scheme, the wet environmental air passes through an evaporation coil, where an evaporating refrigerant fluid absorbs part of the thermal energy, causing an air temperature decrease below the dew point. The first two useful effects of that passage are a flow of dry and cooled air and a mass of condensed water. In simple AWG machines, the airflow is discharged into the environment and the only effect of the process that is actually used is the condensed water. Instead, the integrated system is designed to permit, not only the collection of the condensed water, but also the use of the dry and cooled air. Such an airflow can be conveyed to the existing air treatment unit of a standard air conditioning system, or directly to air ducts of a mechanical ventilation system as primary air. The condensed water, in both types of machines (simple and integrated), is collected and delivered to the treatment system in order to obtain the required water quality.

The refrigerant that has absorbed the heat from the air after compression is delivered to a second coil, the condenser. The third possible useful effect of such a scheme is provided by the condensation heat coming from the refrigerant, which must discharge the energy absorbed from the treated air and from the compressor in order to return to the beginning of the cycle. In simple AWG machines, such a thermal energy is discharged into environmental air, and is thus wasted. On the other hand, in integrated systems, the design and the cycle control permit the use of that energy in order to heat up a thermal vector. In 
the example of Figure 1, the condenser is connected to a water heat exchanger in order to obtain domestic water heating.

The description above highlights that AWG-integrated machines, with the same energy required by a simple AWG machine, are able to provide water and the same time they can cover, at least in part, the heating and cooling needs of a building, as shown in [16]. Obviously, the efficiency of integrated machines in terms of energy use is far higher than that of simple AWG machines. Such a solution can be very competitive, not only in comparison to simple AWG machines, but also in comparison to conventional air conditioning and water-heating systems, or even in comparison to advanced air-conditioning-integrated systems.

Some of the first existing examples of AWG-integrated machines already in use are able to exploit both, or at least one, of the byproducts of the compression reverse cycle [37].

In the next sections, after a brief review of the WET equation, the GEI formulation will be introduced, comprising the extended version that permits comparison between AWGs and conventional or integrated HVAC systems, and also a comparison of integrated HVACs among themselves. Formulations will be further explained by means of a practical explanation, and then two calculation examples of GEI will close the section.

\subsection{WET Indicator}

Before introducing the global index formulation, it is necessary to briefly remember the WET indicator expression, presented in [18], which was proposed to depict the energy effectiveness related to the useful effect of water production for AWGs. Such an indicator is the ratio between water condensation energy, which is the wanted useful effect, and the energy required by the whole system in order to obtain such a condensation. Its formulation is an evolution of an existing energy indicator, the specific energy consumption (SEC) of the condensed water [21].

As a matter of fact, WET has the same structure of EER and COP, because it was established from the beginning to be used with them in order to obtain GEI.

WET formulation permits to translate the water extracted from air into energy by means of the latent heat of condensation.

If the specific consumption for water production is known, WET can be expressed as:

$$
\mathrm{WET}=\frac{\rho \cdot Q_{c}}{\mathrm{SEC} \cdot 3600}
$$

where

SEC = ratio between energy consumption and produced water $\left[\mathrm{kWh} / \mathrm{dm}^{3}\right]$

$Q_{c}=$ latent heat of condensation per unit mass $[\mathrm{kJ} / \mathrm{kg}]$

$\rho=$ water density in liquid phase, assumed $1 \mathrm{~kg} / \mathrm{dm}^{3}$

Latent heat of condensation, $Q_{c}$, depends on temperature, $t\left({ }^{\circ} \mathrm{C}\right)$; in a range of temperatures compatible with AWG technology, it can be calculated as follows [38]:

$$
Q_{c}=2500.8-2.36 \cdot t+0.0016 \cdot t^{2}-0.00006 \cdot t^{3}
$$

Nevertheless, as explained in [18], $Q_{c}$ can be assumed to be constant and equal to $2460 \mathrm{~kJ} / \mathrm{kg}$ in first approximation, because for the most widespread AWG working range, the error that can occur using such a constant instead of the function is below $0.89 \%$.

If the daily or hourly water production and related energy consumption are given separately, the WET expression becomes:

$$
\mathrm{WET}=\frac{w \cdot \rho \cdot Q_{c}}{e n}
$$

where

$w=$ hourly or daily water production $\left[\mathrm{m}^{3}\right]$ 
en = energy consumption required by the system to produce water [kJ]

$\rho=$ water density in liquid phase, assumed $1000 \mathrm{~kg} / \mathrm{m}^{3}$

The water condensation energy, $Q_{w}(\mathrm{~kJ})$, can be expressed as follows:

$$
Q_{w}=w \cdot \rho \cdot Q c
$$

so WET can be compactly expressed as:

$$
\mathrm{WET}=\frac{Q_{w}}{e n}
$$

\subsection{Global Evaluation Index (GEI) Proposal}

The idea behind the GEI formulation comes from the consideration that a single machine, able to provide a number of $n$ useful effects while consuming a quantity of energy equal to $e n$, has an efficiency $n$ times higher than a set of $n$ machines, each one consuming an energy quantity equal to en to provide a single useful effect only. On the basis of such a consideration, the authors define such an index as follows:

$$
\mathrm{GEI}=I d \cdot \sum_{i=1}^{I d} E_{i}
$$

where

$I d$ = integration degree, corresponding to the number of useful effects provided simultaneously with the same energy input;

$E_{i}=i$-th efficiency, or $i$-th useful effect indicator (i.e., WET, COP, EER).

This general expression permits to take the indicators mentioned above into account, but it could also take any other useful effect indicator into account and thus can be applied, not only to integrated AWGs, but also to integrated HVAC systems. Such an index was built without weighing each term of the sum, in order to avoid questionable personal choices, one of the main criticisms underlined by [17], by introducing a single multiplication factor, Id. It is important to underline that the value of such a factor is not derived from any aleatory choice, but rather from the objective energetic consideration described above. The index has been studied to permit an immediate comparison between different combinations of integrated machines, and also between integrated and equivalent combinations of nonintegrated machines (in terms of useful effects). As a matter of fact, such a formulation is suitable to compare, not only two homogeneous machines, but also different combinations of HVAC and/or AWG systems, simply by defining the equivalent GEI, GEI $\mathrm{I}_{\mathrm{eq}}$, as the sum of the GEI indices of every machine involved in the system:

$$
\mathrm{GEI}_{\mathrm{eq}}=\sum_{j=1}^{n} \mathrm{GEI}_{j}
$$

where

$n=$ number of machines composing the system.

In both formulations, the result is a single number, greater than zero, and the higher the value of GEI and/or $\mathrm{GEI}_{\mathrm{eq}}$ is, the higher the global efficiency of the system.

\subsection{GEI Practical Explanation: Comparison between an Integrated AWG and Three Single Effect Machines}

The physical meaning of GEI formulation, from the energy efficiency point of view, can be made clear by a comparison between an AWG-integrated system (referring to the scheme in Figure 1) and a set of three single conventional machines, indicated as $M_{1}, M_{2}$, and $\mathrm{M}_{3}$. 
The first conventional machine, $\mathrm{M}_{1}$, provides heating energy, and its energetic behavior is represented by its COP.

$\mathrm{COP}_{1}=Q_{h} / e n=$ heating energy divided by consumed energy.

$\mathrm{M}_{2}$ provides cooling energy, and its energetic behavior is represented by its EER.

$\mathrm{EER}_{2}=Q_{c} / e n=$ cooling energy divided by consumed energy.

$\mathrm{M}_{3}$ provides water extraction from air by vapor condensation, and its energetic behavior is represented by its WET.

$\mathrm{WET}_{3}=Q_{w} / e n=$ water condensation energy divided by consumed energy.

The overall energetic behavior of the whole set, that is, the ratio between the whole energy obtained from the three machines, the useful effects, and the total consumed energy, is:

$$
\frac{Q_{h}+Q_{c}+Q_{w}}{e n+e n+e n}=\frac{\mathrm{COP}_{1}+\mathrm{EER}_{2}+\mathrm{WET}_{3}}{3}
$$

The integrated AWG that provides the same three useful effects, $Q_{h}, Q_{c}$, and $Q_{w}$, consumes only one $e n$. Its energetic behavior, thus, is:

$$
\frac{Q_{h}+Q_{c}+Q_{w}}{e n}=\mathrm{COP}_{1}+\mathrm{EER}_{2}+\mathrm{WET}_{3}
$$

Comparing (8) and (9), it is clear that the energetic behavior of the integrated machine is three times more efficient than that of the set of conventional ones.

The GEI calculation exactly provides such information, as can be seen in the following.

For the set of single machines, applying (6) and remembering that $I d=1$, as each machine provides only one useful effect, it can be written:

$$
\begin{aligned}
\mathrm{GEI}_{1} & =1 \cdot \sum_{i=1}^{1} E_{i}=\mathrm{COP}_{1} \\
\mathrm{GEI}_{2} & =1 \cdot \sum_{i=1}^{1} E_{i}=\mathrm{EER}_{2} \\
\mathrm{GEI}_{3} & =1 \cdot \sum_{i=1}^{1} E_{i}=\mathrm{WET}_{3}
\end{aligned}
$$

Applying Equation (7), it is possible to determine the $\mathrm{GEI}_{\mathrm{eq}}$ of the set of the three machines (called, in the formulation below, "discrete" in order to underline that the three useful effects are provided by separated single machines):

$$
\mathrm{GEI}_{\text {eq discrete }}=\mathrm{COP}_{1}+\mathrm{EER}_{2}+\mathrm{WET}_{3}
$$

For the integrated AWG machine, applying (6), it is possible to write:

$$
\mathrm{GEI}_{\text {integrated }}=\mathrm{GEI}=3\left(\mathrm{COP}_{1}+\mathrm{EER}_{2}+\mathrm{WET}_{3}\right)
$$

where

$I d=3$, because the machine provides three useful effects at the same time with the same energy consumption.

From the comparison between (13) and (14), it is evident that the GEI of the integrated machine is three times that of the set composed by the three single machines:

$$
\mathrm{GEI}_{\text {integrated }}=3 \cdot \mathrm{GEI}_{\mathrm{eq} \text { discrete }}
$$

The result shows that GEI depicts the energy behaviour of the two systems, directly using the integration degree to provide a measure of the energy efficiency. 
Applying Equation (6) for a comparison among two or more homogenous integrated systems, characterized by providing the same number of useful effects, the result will be a comparison between the sum of COP and/or EER and/or WET (apart from the Id multiplication factor, which will be the same and thus not influence in the final result). Such a result is in agreement with [14]. In the next section the first application of GEI is presented and how GEI overcomes the overall COP issue is discussed, as mentioned in the literature review.

\subsection{GEI Application: Comparison between Two Different Machines}

In the current section, the first example of GEI use is shown. The index is employed to determine the best solution for two cases. Case 1 regards the judgment between two homogenous integrated machines, each one providing the same number of useful effects. Case 2 regards two non-homogenous systems; two machines providing a different number of useful effects. In addition to GEI the overall COP calculation for both cases is also presented in order to understand how GEI overcomes the overall COP issue.

\subsubsection{Case 1-Homogenous Systems}

In this case, a comparison between two homogenous systems (two different models of AWG-integrated machines) is carried out. Both of them use electrical power and are able to provide three useful effects: water and, at the same time, cooling energy and heating energy.

Both machines are based on a compression reverse cycle (the most diffused technology). In this case, their efficiency performances are described by means of three different indicators, each one specifically dedicated to one of the useful effects: WET is related to water production efficiency, EER is the cooling efficiency and COP is the heating efficiency. The average production capability and absorption characteristics, in terms of power, are known and reported in Table 1. In the same table, each single efficiency indicator value is also reported.

Table 1. Average performance characteristics of the two machines.

\begin{tabular}{cccccccc}
\hline & $\boldsymbol{P}_{\boldsymbol{h}}[\mathbf{k W}]$ & $\boldsymbol{P}_{\boldsymbol{c}}[\mathbf{k W}]$ & $\boldsymbol{P}_{\boldsymbol{w}}[\mathbf{k W}]$ & $\boldsymbol{P}[\mathbf{k W}]$ & $\mathbf{C O P}$ & EER & WET \\
\hline Machine 1 & 30 & 20 & 20 & 10 & 3 & 2 & 2 \\
\hline Machine 2 & 40 & 30 & 10 & 10 & 4 & 3 & 1 \\
\hline
\end{tabular}

Where $P_{h}=$ heating power $[\mathrm{kW}] ; P_{c}=$ cooling power $[\mathrm{kW}] ; P_{w}=$ water condensation power $[\mathrm{kW}] ; P=$ input power $[\mathrm{kW}]$.

In order to understand what is the best solution from the energy point of view, overall COP and GEI are calculated.

Following [14], the overall COP can be calculated as:

$$
\mathrm{COP}_{\text {overall }}=\frac{P_{h}+P_{c}+P_{w}}{P}
$$

The highest value of overall COP determines the best machine.

Applying (14) to the current case:

$$
\begin{aligned}
& \text { Overall COP } 1=(30+20+20) / 10=7 \\
& \text { Overall } \mathrm{COP}_{2}=(40+30+10) / 10=8
\end{aligned}
$$

Using overall COP, the best choice is machine 2.

Applying (6), it is possible to obtain the GEI values:

$$
\begin{aligned}
& \mathrm{GEI}_{1}=3(3+2+2)=21 \\
& \mathrm{GEI}_{2}=3(4+3+1)=24
\end{aligned}
$$


The ratios between overall $\mathrm{COP}_{\mathrm{S}}$ and between $\mathrm{GEI}_{\mathrm{S}}$ are the same, thus, in this case, GEI gives the same level of information as the other index - the best machine is number 2 .

As already stated, in the case of comparison between integrated systems with a homogenous integration degree (the same number of useful effects) GEI and overall COP are in agreement.

\subsubsection{Case 2-Non-Homogenous Systems}

This second application concerns two non-homogenous systems. In this case, the difference between the two approaches, GEI and overall COP, can be better appreciated.

There are two plant configurations, both absorbing the same electrical power input of $2 \mathrm{~kW}$. The first one is composed of two separated pieces of equipment:

- 1 heat pump, characterized by a COP of 6 ;

- 1 cooling cycle, characterized by a EER of 3 .

Such a plant configuration, with a power input of $2 \mathrm{~kW}$, giving $6 \mathrm{~kW}$ of heating power, can give $3 \mathrm{~kW}$ of cooling power.

The second plant configuration is composed of an integrated machine, giving at the same time:

- Heating energy with a COP of 3

- $\quad$ Cooling energy with a EER of 2

This second system, with the same power input as the first system $(2 \mathrm{~kW})$, and the same output of $6 \mathrm{~kW}$ of heating power, can give $4 \mathrm{~kW}$ of cooling power.

In Case 2, the indicators used to describe the efficiency of each machine are the COP and EER, because the useful effects are heating and cooling, both of them provided by means of a reverse cycle.

Taking into account (16), the overall COP for the second plant configuration is 5 . Now, it is not clear how to compare such a number with the performances of the first plant configuration: how to manage it and how to compare it with the efficiency parameters (EER or COP) of each equipment of the first plant configuration.

If the comparison is carried out between the overall COP and the EER of the cooling cycle of the first plant configuration, it is:

$$
\mathrm{COP}_{\text {overall }}=5>\mathrm{EER}=3
$$

Thus, the integrated machine actually seems like a better solution, as what concerns the cooling effect, and that it is true, because with the same overall consumption, $2 \mathrm{~kW}$, it can give $4 \mathrm{~kW}$ of cooling instead of $3 \mathrm{~kW}$ given by the first plant configuration.

However, if the overall COP is compared to the COP of the heat pump of the first plant configuration, it becomes:

$$
\mathrm{COP}_{\text {overall }}=5<\mathrm{COP}=6
$$

By means of this second comparison, the first plant configuration seems better than the integrated machine, and that is not true because the integrated machine is equivalent from a heating point of view, it has the same overall consumption, $2 \mathrm{~kW}$, and gives the same thermal power $(6 \mathrm{~kW})$.

It can be concluded that it is not immediate known how to directly derive a judgment simply using the overall COP.

If, instead of the overall COP, the GEI index is taken into account, it is clear that system number 2 is better than the first, because, applying (7), it can be calculated as:

$$
\begin{gathered}
\mathrm{GEI}_{\mathrm{eq} 1}=6+3=9 \\
\mathrm{GEI}_{\mathrm{eq} 2}=\mathrm{GEI}_{2}=2(3+2)=10
\end{gathered}
$$


Such a result is correct because the integrated machine, with the same power, provides the same thermal power, but has a better behaviour in terms of cooling capacity.

It can be noted that GEI exactly gives the sum of all the useful effects provided by each one of the two systems, given the same energy input.

It can be concluded that GEI can be used, not only for a comparison among homogeneous machines (machines providing the same number of useful effects), as happens for overall COP, but also for plant configurations comprising non-homogeneous systems.

\subsection{Energy Consumption and Primary Energy: Some Notes}

GEI is defined on the basis of energy consumption, as happens for its related indicators, COP, EER, and WET. When a compressor reverse cycle is taken into account, usually, its energy input is only electricity. In that case, the consumption will be homogeneously expressed in terms of electrical consumption; however, GEI formulation is a general one and it can be applied to different plant configurations, using various energy sources, types, and vectors. For example, a plant configuration can happen to comprise a combination of a boiler, powered by methane, and a compressor reverse cycle machine, powered by electricity from the grid. The reverse cycle provides air conditioning and a heating fraction, at low temperature, while the boiler is used to achieve a target temperature. If such a configuration is to be compared with a combination of an electrical boiler, fed by photovoltaic panels, and a conventional air conditioning, powered by the grid, providing the same useful effects, the first step is to translate each energy consumption into homogenous terms. In the example, energy coming from methane must be transformed in a form comparable to electricity, and the same must be done for electricity coming from photovoltaic.

A diffused mean to overcome such an issue is to express each energy consumption value in primary energy using conversion factors [39]. Such factors can vary year by year and country by country, for example, in standard EN ISO 52000-1 [40]. This is because conversion factors, which are the ratio between primary energy required to produce the delivered energy and the delivered energy itself, depend upon many local factors, such as: energy chain configuration, energy mix composition, and plants efficiency. Therefore, it is clear that, when a comparison between non-homogenous energy inputs must be carried out, it is important to state the plant location and thus the related conversion factors. Such a preliminary operation must be carried out also for GEI calculation in terms of primary energy. Such a calculation, once determined the local conversion factors, consists simply in dividing GEI for them.

$$
\mathrm{GEI}_{\text {primary }}=\frac{\mathrm{GEI}}{f}
$$

where

$\mathrm{GEI}_{\text {primary }}=$ index expressed in terms of primary energy

$\mathrm{GEI}$ = index calculated taking into account the energy source required by the investigated machine $f=$ primary energy conversion factor.

The above formulation can be also written as:

$$
\mathrm{GEI}_{\text {primary }}=I d \cdot \sum_{i=1}^{I d} \frac{E_{i}}{f}
$$

Obviously, whenever $\mathrm{GEI}_{\mathrm{s}}$ are expressed in terms of primary energy, also $\mathrm{GEI}_{\mathrm{eq}}$ will be expressed in the same way:

$$
\mathrm{GEI}_{\text {eq primary }}=\sum_{j=1}^{n} \mathrm{GEI}_{j \text { primary }}
$$

By means of this formulation, taking into account primary energy, it is possible to compare, not only reverse cycle-based systems, but also system combinations comprising fuel powered boilers, electrical boilers, and so on. 


\section{GEI Application to a Case-Study}

In the current section, a calculation of GEI applied to a real case is presented, based on a new calculation on the data presented by authors of previous research [16]. Such a case was chosen because it regards a real installation of an integrated AWG machine on an existing building, a hotel in Villahermosa, Mexico. The integrated machine was placed on the roof of the hotel in 2017, and its behaviour was tested for 21 days. The integrated AWG, based on a compression reverse cycle, treated external air to provide water, a heating flux, and a dry and cool air flux. The hotel had a conventional plant, comprising air conditioning and an LPG boiler for domestic water heating. Data regarding the energetic behaviour of the existing plants were also collected. In the current work, data coming from previous research were elaborated with new settings and were used as the starting point to calculate the index and to determine if the AWG integrated system is more advantageous in comparison to the other two plant configurations. The first configuration is composed of the actual hotel plant for heating and air conditioning, plus a normal AWG. The second one is composed of advanced air conditioning, able to provide two useful effects, plus a normal AWG. The term "normal" in this context identifies an AWG only able to produce water.

The scheme of the integrated AWG is reported in Figure 1, while its main characteristics are summarized as follows:

- Cooling circuit, equipped with a screw compressor, with a nominal cooling capacity of $100 \mathrm{~kW}$;

- Air treatment unit, equipped by evaporation coil for direct evaporation of the coolant (R134a) and water from air condensation. The air treatment unit is equipped also with a heat recovery system;

- Coolant condensation heat recovery provided by a plate fin heat exchanger linked to a domestic water circuit, nominal heating capacity: $120 \mathrm{~kW}$;

- Condensed water treatment system.

As already noted, the integrated system is based on a compression reverse cycle, thus the electrical energy input gives, at the same time, three useful effects:

- A cooling effect, under the form of a dry cooled air flux released by the evaporator after the water extraction, that can be quantified into the cooling energy $Q_{c}$;

- A heating effect, that is the thermal energy released by the condenser, which can be quantified into heating energy $Q_{h}$;

- Condensed water, which can be quantified into the water condensation energy $Q_{w}$.

The scheme of energy input and outputs is shown in Figure 2.

In [16], on the basis of the experimental results, the AWG-integrated machine's yearly behaviour, in terms of produced water, heating, cooling, and energy consumption, was determined. In the current research, the monthly behaviour, in the same terms, was calculated, imposing a new setting for the machine. In particular, domestic water temperature was set at $45^{\circ} \mathrm{C}$, closer to standard conditions [41] that set the conventional domestic water temperature at $42{ }^{\circ} \mathrm{C}$ at the user's point, and the compressor was set at its most frequent working conditions. Results of these new calculations, expressed in terms of hourly water production, heating, and cooling energy production and energy consumption are shown in Figure 3. The yearly average results, reported in Figure 3, are summarized in Table 2.

Table 2 permits to appreciate how much the integrated machine acts as a heat pump and as a cooling system at the same time, as well as an air-to-water generator. The energy electrical input is all the machine needs to provide the three effects, and, of course, the thermal effects are higher than the electrical input, as happens in all reverse cycles. 


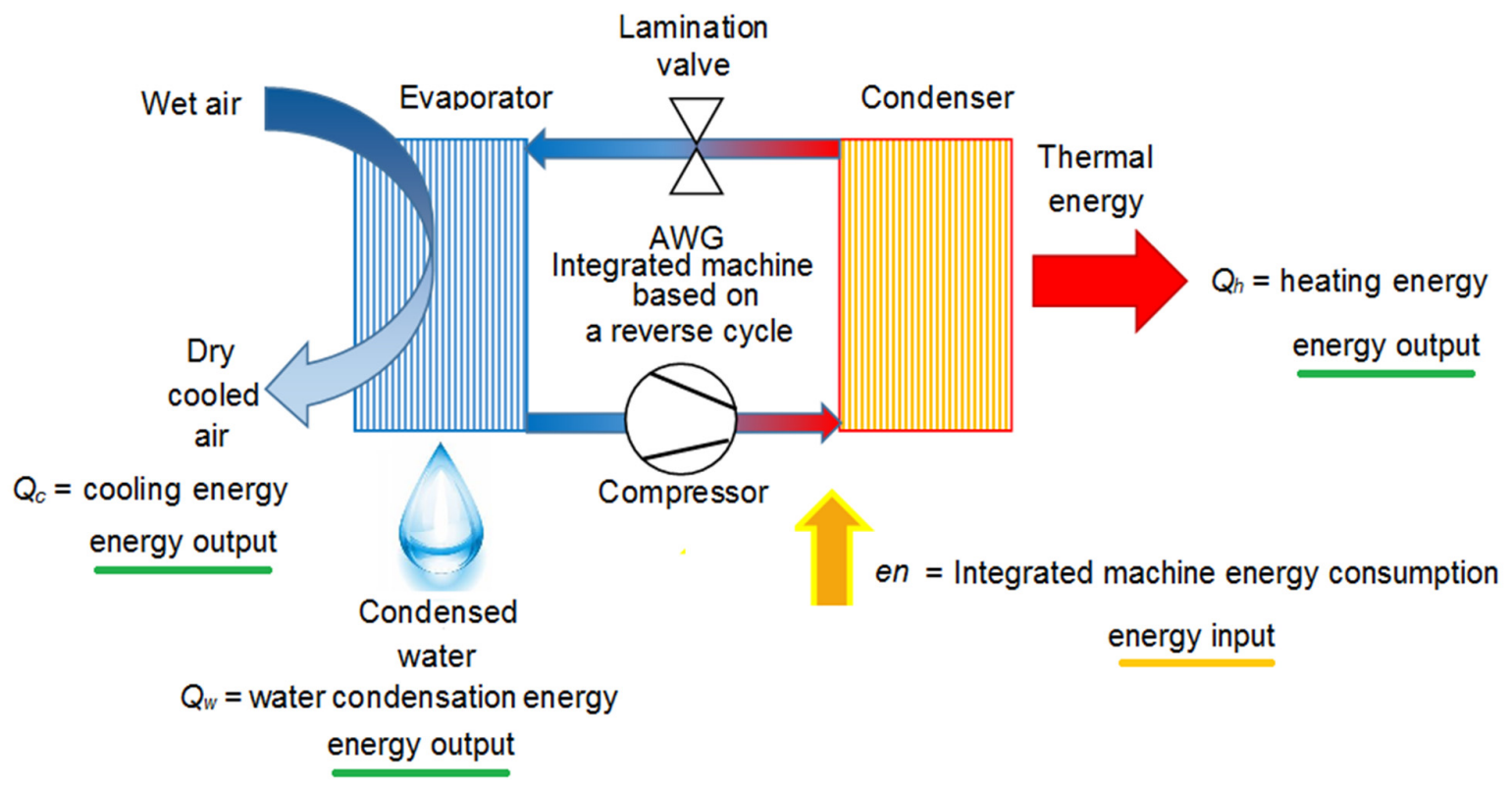

Figure 2. AWG-integrated machine: energy input and outputs.

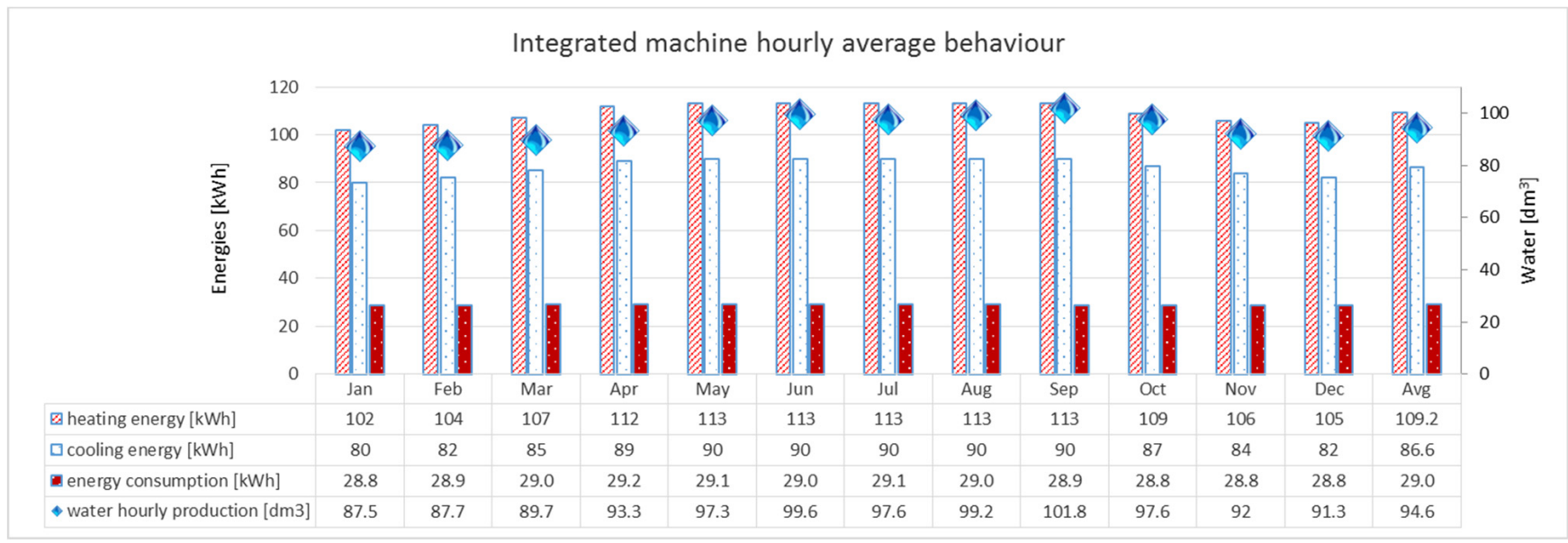

Figure 3. Integrated machine average hourly behaviour, month by month.

Table 2. AWG-integrated machine hourly behaviour averaged over the year, expressed as water production, heating, cooling energy and energy consumption.

\begin{tabular}{cccc}
\hline Water Production & Heating Energy & Cooling Energy & Energy Consumption \\
\hline$\left[\mathrm{dm}^{3} / \mathrm{h}\right]$ or $[\mathrm{L} / \mathrm{h}]$ & {$[\mathrm{kWh}]$} & {$[\mathrm{kWh}]$} & {$[\mathrm{kWh}]$} \\
\hline 94.6 & 109.2 & 86.6 & 29 \\
\hline
\end{tabular}

Another interesting point to be underlined is that the said energy input takes into account the electrical consumption of the entire integrated machine, thus the compressor work, evaporation fans work, the lamination valve work, etc., are also included in such a term Moreover, in the said term, all the electrical motor inefficiencies are also taken into account. Providing energy consumption in such a way permits to calculate COP, EER, and WET, following their current common approaches, which define them as the ratio between the useful effect and the entire energy input of the machine (included consumption of the ancillary items, such as fans, pumps, etc., and by considering efficiencies). Obviously, the sum between the cooling energy and the energy consumption, defined in such a way, exceeds the heating energy, as can be confirmed considering the values reported in Table 2 and/or in Figure 3. 
It is interesting to underline that average yearly results are not very different from monthly results. For example, the maximum deviation in water production is $\pm 7.6 \%$. As the considered integrated AWG machine is based on a compression reverse cycle, and treats external air, its energetic behaviour depends on external environmental air thermohygrometric conditions [18]. In the current case, the behaviour of the integrated machine is not very variable, because the Villahermosa climate is reasonably stable and there are no high excursions in the thermo-hygrometric parameters each month, as it can be observed in Figure 4. In the figure, hourly environmental data, based on the statistics of the last five years, coming from the weather station of Carlos Rovirosa Perez International Airport, Mexico, were arranged by the authors into a graph.

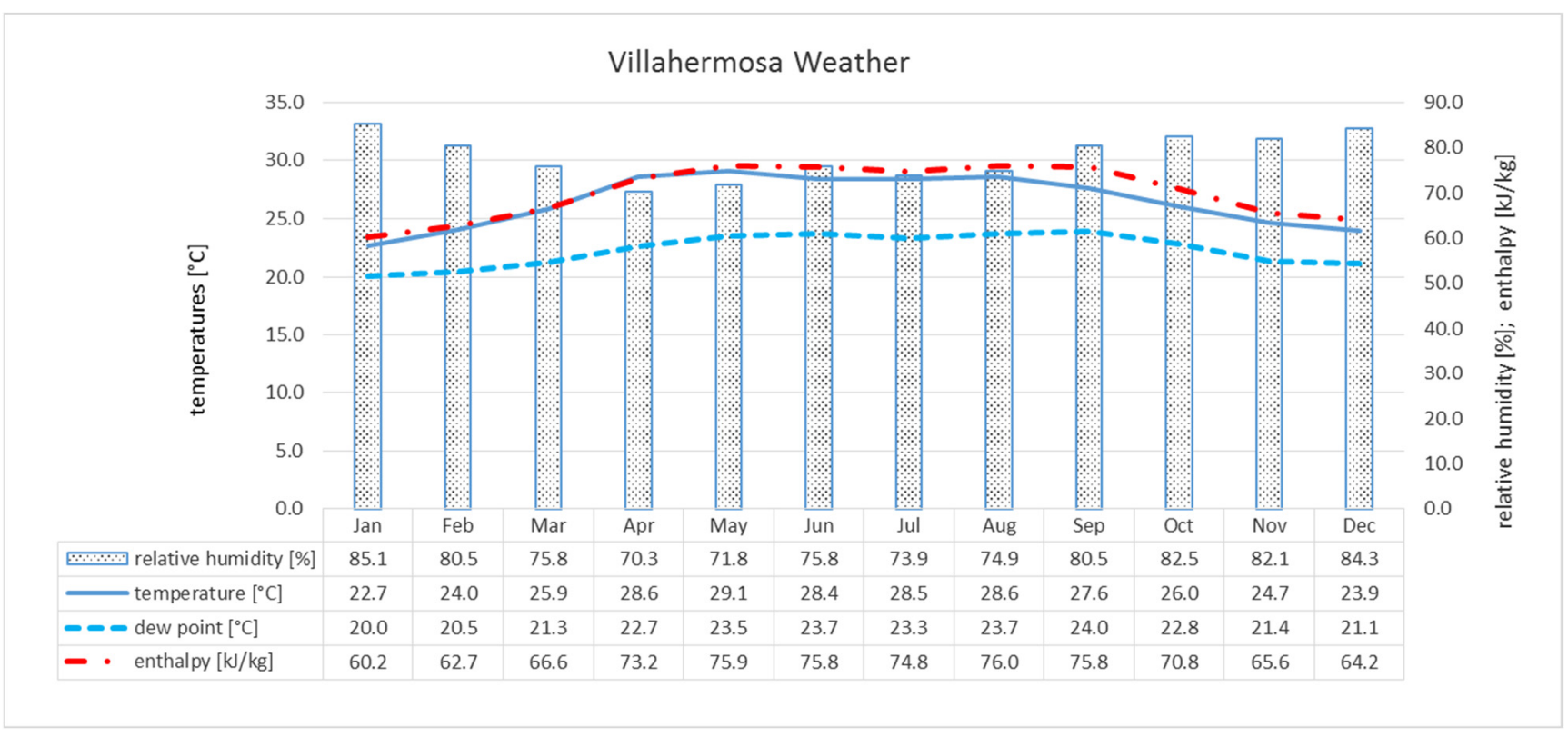

Figure 4. Villahermosa main weather parameter behaviour during the year.

As noted above, the AWG-integrated machine gives water, heating power, and cooling power. Its WET, COP, EER, and GEI were calculated on the basis of average results. The indicator and index results are shown in Table 3, where GEI is expressed in terms of primary energy. Conversion factor $f$ from electricity to primary energy was stated to be equal to 1.8 , taking an average electricity generation efficiency in Mexico of about 55\% [42].

Table 3. GEI results for the integrated AWG.

\begin{tabular}{|c|c|c|c|}
\hline Efficiency Indicator & Formulation & Calculations & Results \\
\hline WET & $\frac{Q_{w}}{e n}$ & $\begin{aligned} Q_{w}= & 0.00946 \mathrm{~m}^{3} \cdot 1000 \frac{\mathrm{kg}}{\mathrm{m}^{3}} \cdot 2460 \frac{\mathrm{kJ}}{\mathrm{kg}}=232,761 \mathrm{~kJ} \\
& \text { en }=29 \mathrm{kWh} \cdot 3600 \mathrm{~s}=104,400 \mathrm{~kJ}\end{aligned}$ & 2.23 \\
\hline $\mathrm{COP}$ & $\frac{Q_{h}}{e n}$ & $Q_{h}=109.2 \mathrm{kWh} \cdot 3600 \mathrm{~s}=393,120 \mathrm{~kJ}$ & 3.77 \\
\hline EER & $\frac{Q_{c}}{e n}$ & $Q_{c}=86.6 \mathrm{kWh} \cdot 3600 \mathrm{~s}=311,760$ & 2.99 \\
\hline Index & Formulation & Calculations & Results \\
\hline GEI & $I d \cdot \sum_{i=1}^{I d} E_{i}$ & $I d=$ heating + cooling + water $=3$ & 26.97 \\
\hline $\mathrm{GEI}_{\text {primary }}$ & $\frac{\mathrm{GEI}_{e l}}{f}$ & $f=1.8$ & 14.98 \\
\hline
\end{tabular}

The first plant configuration, used to compare the above results, consists in the following three machines: 
- Actual hotel LPG boiler, with a nominal heating power of $820 \mathrm{~kW}$ and an efficiency $(\eta)$ of 0.7 ;

- Actual hotel air conditioning system, with a yearly average EER of 3.5;

- $\quad$ Simple AWG machine, with a yearly WET average of 2.23.

Data related to the boiler efficiency and air conditioning system come from [16], while WET is the same as the integrated machine. Values are reported in Table 4. For each machine composing the system, the GEI value is the same as the efficiency indicator, because each of them can provide only one useful effect; the $f$ value for LPG, stated to equal 1.1, comes from [40] In Table $5 \mathrm{GEI}_{\text {eq primary }}$ result is reported.

Table 4. $\mathrm{GEI}_{\mathrm{s}}$ calculation for the second configuration.

\begin{tabular}{ccccccc}
\hline Efficiency Indicator & Value & Energy Input & $f$ & $\boldsymbol{I} \boldsymbol{d}$ & GEI $_{\boldsymbol{i}}$ primary & Results \\
\hline WET & 2.23 & Electricity & 1.8 & 1 & $1 \cdot \frac{2.23}{1.8}$ & 1.24 \\
\hline$\eta$ & 0.7 & LPG & 1.1 & 1 & $1 \cdot \frac{0.7}{1.1}$ & 0.64 \\
\hline EER & 3.5 & Electricity & 1.8 & 1 & $1 \cdot \frac{3.5}{1.8}$ & 1.94 \\
\hline
\end{tabular}

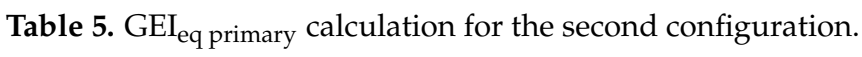

\begin{tabular}{clc}
\hline Index & Formulation & Results \\
\hline GEI $_{\text {eq primary }}$ & $\sum_{i=1}^{I d}$ GEI $_{i \text { primary }}$ & 3.81 \\
\hline
\end{tabular}

Comparing the new index values, it is easy to understand that the integrated machine, even if it is less efficient in the field of cooling, is far more efficient in absolute terms of energy exploitation. The ratio between the two results indicates that the first solution is 3.9 times more efficient, from a useful effect point of view.

A second comparison was carried out supposing to revamp the actual air conditioning system, above described, and transforming it into an integrated machine. The revamped equipment, by means of a coolant circuit modification and a plate heat exchanger, is able to exploit the condensation heat to heat up domestic water, as well as provide the cooling energy. Supposing that the average EER remains equal to 3.5, the average COP can be set equal to 4.5 .

This second configuration, thus, consists of the following two machines:

- Revamped air conditioning, able to provide cooling and heating, characterized by yearly average COP and EER, respectively, of 4.5 and 3.5;

- Simple AWG machine, with a yearly average WET of 2.23;

In Table 6 the performances of the updated second configuration, composed of the cooling/heating integrated system and the same simple AWG machine are summarized.

Table 6. $\mathrm{GEI}_{\mathrm{s}}$ calculation for the modified second plant configuration.

\begin{tabular}{ccccccc}
\hline Indicator & Value & Energy Input & $f$ & Id & GEI $_{\boldsymbol{i} \text { primary }}$ & Results \\
\hline WET & 2.23 & Electricity & 1.8 & 1 & $1 \cdot \frac{2.23}{1.8}$ & 1.24 \\
\hline COP & 4.5 & Electricity & 1.8 & & $2 \cdot\left(\frac{3.5}{1.8}+\frac{4.5}{1.8}\right)$ & 8.89 \\
\hline EER & 3.5 & Electricity & 1.8 & 2 & & \\
\hline
\end{tabular}

In Table 7, the GEI related to this new configuration is calculated. Its value, equal to 10.13 , is decidedly increased in comparison to the previous one, which was 3.81. Such a result easily demonstrates the increased effectiveness of the plant improvement, but the same results show that this new configuration is still less efficient than the first one, composed by only the AWG integrated machine. As a matter of fact, the most integrated solution is still $48 \%$ more efficient than the improved second configuration. 
Table 7. $\mathrm{GEI}_{\text {eq primary }}$ calculation for the modified second plant configuration.

\begin{tabular}{clc}
\hline Index & Formulation & Results \\
\hline GEI $_{\text {eq primary }}$ & $\sum_{i=1}^{I d} \mathrm{GEI}_{i \text { primary }}$ & 10.13 \\
\hline
\end{tabular}

\section{Observations on GEI Application to Heterogeneous Combination of Plants}

The formulation of GEI can also be applied in heterogeneous situations, where integrated machines are combined with traditional ones, and cover only a part of the thermal needs.

In this case each $\mathrm{GEI}_{\mathrm{s}}$, composing the $\mathrm{GEI}_{\mathrm{eq}}$, must be evaluated weighing the influence of each component of the plant on the global amount of useful effects provided by it. Such a weighting can be easily done taking the fraction between the energy, consumed by each component of the plant system configuration and the whole energy consumption into account. The expression of the equivalent GEI becomes:

$$
\mathrm{GEI}_{\mathrm{eq}}=\sum_{j=1}^{n} \frac{e n_{j}}{e n} \mathrm{GEI}_{j}
$$

The expression can also be written referring to the fraction of power required by each component, as follows:

$$
\mathrm{GEI}_{\mathrm{eq}}=\sum_{j=1}^{n} \frac{P_{j}}{P} \mathrm{GEI}_{j}
$$

The following proposed example of $\mathrm{GEI}_{\mathrm{eq}}$ calculation can be useful to show how the index can be easily determined also in those cases where integrated and non-integrated machines work together in order to cover the all useful effect demands.

It was considered to combine the integrated machine described in the previous section with a conventional air conditioning system, powered by electrical energy, which provides a cooling power of $100 \mathrm{~kW}$ with an average EER of 4 .

In this specific case, translation in primary energy is not required because all the employed machines under evaluation use electrical energy as a power supply. In order to calculate $\mathrm{GEI}_{\mathrm{eq}}$, the energy absorbed by each machine must be evaluated.

In particular, in this case, the cooling energy useful effect is provided partially by the integrated machine and partially by the conventional air conditioning system.

The entire useful effect of cooling is:

$$
\text { Cooling power }=186.6 \mathrm{~kW}
$$

Thus, the quantity provided by the integrated machine is $86.6 \mathrm{~kW}$, and the absorbed power is $29 \mathrm{~kW}$ (Table 2).

The GEI of the second machine is 4 and its required energy is $25 \mathrm{~kW}$.

The total power absorption is $54 \mathrm{~kW}$.

Applying (19):

$$
\mathrm{GEI}_{\mathrm{eq}}=\left(26.97 \cdot \frac{29}{54}\right)+\left(4 \cdot \frac{25}{54}\right)=16.34
$$

The GEI $\mathrm{eq}_{\text {, }}$ equal to 16.34 , is obviously less than the previous GEI, which was 26.97 , calculated in the case of maximum integration, with a single machine covering the needs of the entire building.

For application extensions involving HVAC plant combinations comprising solutions powered by traditional and renewable fuels, the conversion of consumed energy into homogenous terms as the described primary energy would be mandatory. 


\section{Conclusions}

The current paper proposes for the first time an index, named GEI, tailored to integrated system evaluations. Such an index answers the current need for a simple and immediate method to compare integrated systems, on the basis of energy efficiency and on the degree of integration. The idea started from the need for a comparison tool for those AWG machines based on a compressor reverse cycle, which are able to transform their by-side products, condensation heat and the dry and cool air coming from the evaporator, into valuable energy sources. The index was studied in order to provide, by means of a single number, information about the global system efficiency. Such a global efficiency is given by the combination between the energy efficiency of each single useful effect and the quantity of useful effects, provided at the same time, with the same energy input by a single system. Moreover, the index formulation was thought to be a combination of existing efficiency indicators, such as WET, COP, EER, etc., in order to be simpler to be calculated.

The index results are numbers greater than zero that increase when the global efficiency increases, thus are very simple to be used as a comparison mean.

The index was formulated as:

- A first equation suitable for comparison among homogenous integrated machines;

- An extended equation, which can be used to compare different combinations of HVAC and AWG systems, also comprising conventional plants;

- A further expression, involving primary energy, that permits to take into account different plant configurations, using various energy sources, types, and vectors

The advantages of the index use have been supported by a calculation example, referring to two different plant cases, application to a case study concerning various types of HVAC plants with different integration levels, and another practical example involving an integrated machine that can cover only a part of the thermal requirements of a building.

(a) The first calculation example, applied to two cases are highlighted:

- How the index can take into account the integration level and the overall efficiency, deriving from the real use of each useful effect of a reverse cycle, combining them in a simple but meaningful way to produce existing efficiency indicators, such as COP, EER, WET, etc.;

- In which way the index overcomes the possible ambiguity related to the overall COP calculation and provides an intuitive metrics for comparisons.

(b) In the case study, three different plant configurations, providing cooling, heating, and water, were described, each one of them characterized by a different degree of integration and different efficiencies. In this case, GEI allowed to carry out an immediate comparison and the results permitted to determine the most efficient solution, avoiding the in depth analysis normally required for integration plant evaluation. For example, the configuration with the maximum plant integration achieved a GEI of 26.97 and a GEI primary value of 14.98, almost four times higher than that achieved by the one characterized by the minimum integration. The result reflects the real efficiency difference of the two configurations.

(c) In the final practical example, the useful effects of an integrated machine covered only a part of the required energy of a building and the rest was given by a non-integrated machine. Results showed again how the index is able to highlight and weigh the role of the integration in order to provide a more accurate estimation of the real overall efficiency of the plant. In this case, the $\mathrm{GEI}_{\mathrm{eq}}$ value was equal to 16.34 , lower than that of the configuration characterized by the maximum integration.

In each example, the index result, as a single number, permitted to immediately identify the most efficient solution, thus, the index can be used in a decision-making phase, moreover, due to its particular formulation and based on existing indicators, can also represent a basic support for future standardization of AWG-integrated machine. 
Author Contributions: Conceptualization, L.C., P.C. and A.M.; Methodology, A.M.; Software, P.C.; Validation, L.C. and P.C.; Formal analysis, L.C. and P.C.; Investigation, A.M. and L.C.; Data Curation, P.C. and L.C.; Writing-Original Draft, L.C.; Writing-Review \& Editing, A.M., L.C. and P.C.; Visualization P.C. and L.C.; Supervision, A.M. All authors have read and agreed to the published version of the manuscript.

Funding: This research received no external funding.

Institutional Review Board Statement: Not applicable.

Informed Consent Statement: Not applicable.

Data Availability Statement: Not applicable.

Conflicts of Interest: The authors declare no conflict of interest.

\section{Nomenclature}

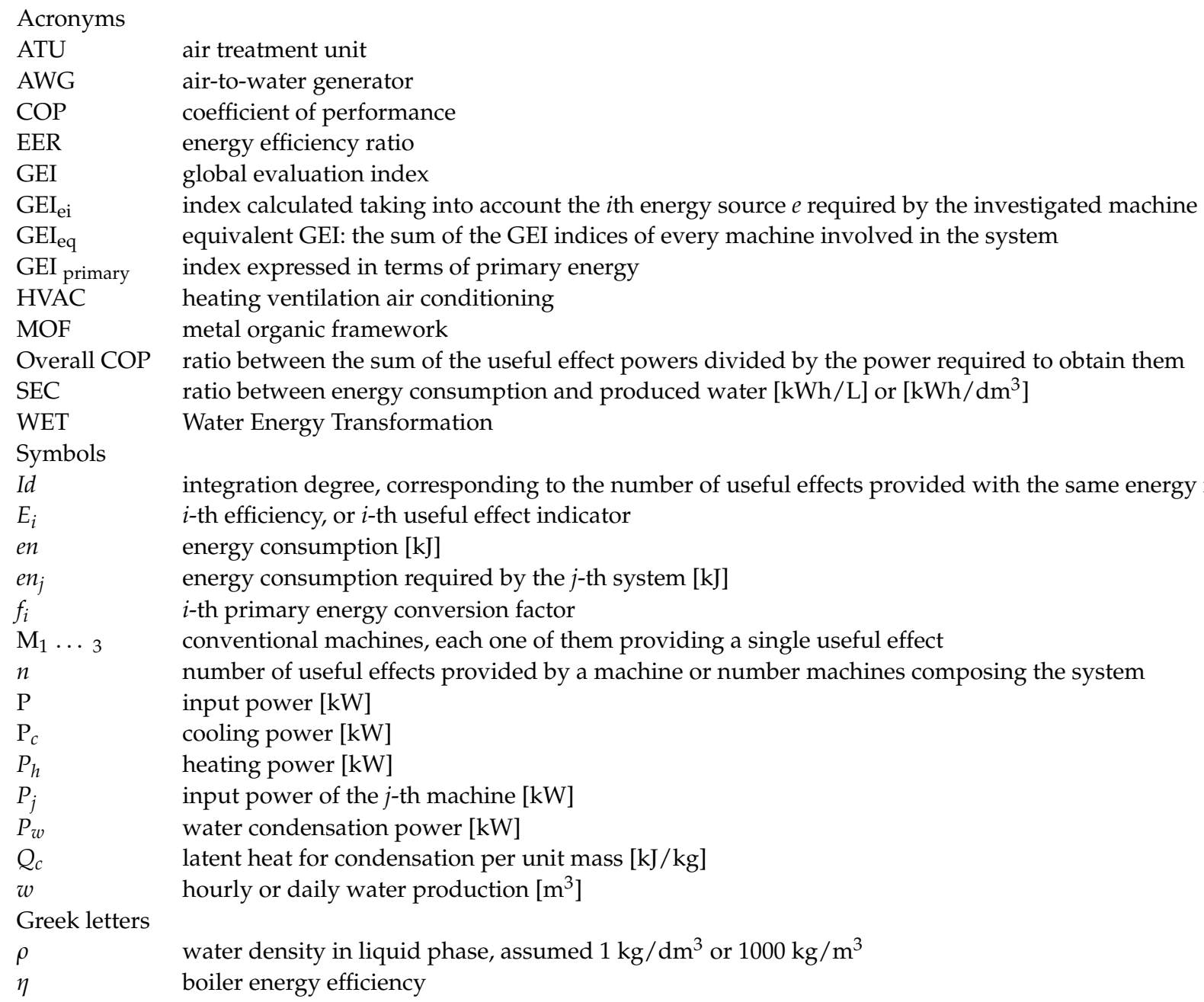

\section{References}

1. World Health Organization. Progress on Household Drinking Water, Sanitation and Hygiene, 2000-2017: Special Focus on Inequalities; World Health Organization: Geneva, Switzerland, 2019.

2. UN-WWAP. The United Nations World Water Development Report 2015: Water for a Sustainable World; UN-WWAP: Paris, France, 2015; ISSN 978-92-3-100071-3.

3. IPCC. Special Report; Climate Change and Land. Available online: https://www.ipcc.ch/srccl/ (accessed on 13 September 2021).

4. Raveesh, G.; Goyal, R.; Tyagi, S. Advances in atmospheric water generation technologies. Energy Convers. Manag. 2021, 239, 114226. [CrossRef]

5. Amaral, R.E.; Brito, J.; Buckman, M.; Drake, E.; Ilatova, E.; Rice, P.; Sabbagh, C.; Voronkin, S.; Abraham, Y.S. Waste Management and Operational Energy for Sustainable Buildings: A Review. Sustainability 2020, 12, 5337. [CrossRef] 
6. Eremia, M.; Toma, L.; Sanduleac, M. The Smart City Concept in the 21st Century. Procedia Eng. 2017, 181, 12-19. [CrossRef]

7. Brunsgaard, C.; Dvořáková, P.; Wyckmans, A.; Stutterecker, W.; Laskari, M.; Almeida, M.; Kabele, K.; Magyar, Z.; Bartkiewicz, P.; Op 't Veld, P. Integrated energy design-Education and training in cross-disciplinary teams implementing energy performance of buildings directive (EPBD). Build. Environ. 2014, 72, 1-14. [CrossRef]

8. Sweden Smart Cities, Best Practice. Available online: https://smartcitysweden.com/best-practice/216/dava-cogeneration-plants/ (accessed on 1 February 2021).

9. A2A Group, Silla 2 Plant. Available online: https://www.a2a.eu/it/gruppo/i-nostri-impianti/termovalorizzatori/silla2 (accessed on 1 February 2021).

10. Onovwiona, H.; Ugursal, V. Residential cogeneration systems: Review of the current technology. Renew. Sustain. Energy Rev. 2006, 10, 389-431. [CrossRef]

11. Lahoud, C.; Al Asmar, J.; Brouche, M. Review of cogeneration and trigeneration systems. Afr. J. Eng. Res. 2018, 6, 39-54. [CrossRef]

12. Ji, J.; Chow, T.-T.; Pei, G.; Dong, J.; He, W. Domestic air-conditioner and integrated water heater for subtropical climate. Appl. Therm. Eng. 2003, 23, 581-592. [CrossRef]

13. Dong, J.; Li, H.; Yao, Y.; Jiang, Y.; Zhang, X. Experimental study on the performance of a multi-functional domestic air conditioner with integrated water heater. Appl. Therm. Eng. 2017, 120, 393-401. [CrossRef]

14. Qiu, F.; Li, B.; Xu, T. Experimental investigations on the thermal performance of a domestic condensing heat recovery airconditioner. Adv. Mech. Eng. 2019, 11, 2. [CrossRef]

15. Magrini, A.; Cattani, L.; Cartesegna, M.; Magnani, L. Water Production from Air Conditioning Systems: Some Evaluations about a Sustainable Use of Resources. Sustainability 2017, 9, 1309. [CrossRef]

16. Cattani, L.; Magrini, A.; Cattani, P. Water Extraction from Air by Refrigeration-Experimental Results from an Integrated System Application. Appl. Sci. 2018, 8, 2262. [CrossRef]

17. Greco, S.; Ishizaka, A.; Tasiou, M.; Torrisi, G. On the Methodological Framework of Composite Indices: A Review of the Issues of Weighting, Aggregation, and Robustness. Soc. Indic. Res. 2019, 141, 61-94. [CrossRef]

18. Cattani, L.; Magrini, A.; Cattani, P. Water Extraction from Air: A Proposal for a New Indicator to Compare Air Water Generators Efficiency. Energies 2021, 14, 224. [CrossRef]

19. Coefficient of Performance (COP). Available online: https://www.sciencedirect.com/topics/engineering/coefficient-of-performance (accessed on 8 February 2021).

20. Energy Efficiency Ratio (EER). Available online: https:/ / www.sciencedirect.com/topics/engineering/energy-efficiency-ratio (accessed on 8 February 2021).

21. Tu, Y.; Wang, R.; Zhang, Y.; Wang, J. Progress and Expectation of Atmospheric Water Harvesting. Joule 2018, 2, 1452-1475. [CrossRef]

22. Al Keyyam, I.; Al-Nimr, M.; Khashan, S.; Keewan, A. A new solar atmospheric water harvesting integrated system using $\mathrm{CPV} / \mathrm{T}$-Stirling engine-Absorption cooling cycle and vapor compression refrigeration cycle. Int. J. Energy Res. 2021, 45, 16400-16417. [CrossRef]

23. Rohde, D.; Andresen, T.; Nord, N. Analysis of an integrated heating and cooling system for a building complex with focus on long-term thermal storage. Appl. Therm. Eng. 2018, 145, 791-803. [CrossRef]

24. Eades, W.G. Energy and water recovery using air-handling unit condensate from laboratory HVAC systems. Sustain. Cities Soc. 2018, 42, 162-175. [CrossRef]

25. Commission Recommendation of 10 July 2003 on Guidance for the Implementation of Regulation (EC) No $761 / 2001$ of the European Parliament and of the Council Allowing Voluntary Participation by Organisations in a Community Eco-Management and Audit Scheme (EMAS) Concerning the Selection and Use of Environmental Performance Indicators (Text with EEA Relevance) (Notified under Document Number C(2003) 2253. ELI. Available online: http:/ / data.europa.eu/eli/reco/2003/532/oj (accessed on 14 June 2021).

26. Goldstein, D.B.; Eley, C. A classification of building energy performance indices. Energy Effic. 2014, 7, 353-375. [CrossRef]

27. Santos, A.F.; Gaspar, P.D.; De Souza, H.J.L. New HVAC Sustainability Index-TWI (Total Water Impact). Energies 2020, 13, 1590. [CrossRef]

28. Santos, A.F.; Gaspar, P.D.; De Souza, H.J. Evaluation of the Heat and Energy Performance of a Datacenter Using a New Efficiency Index: Energy Usage Effectiveness Design—EUED. Braz. Arch. Biol. Technol. 2019, 62, e19190021. [CrossRef]

29. Gido, B.; Friedler, E.; Broday, D.M. Assessment of atmospheric moisture harvesting by direct cooling. Atmos. Res. 2016, 182, 156-162. [CrossRef]

30. Angrisani, G.; Akisawa, A.; Marrasso, E.; Roselli, C.; Sasso, M. Performance assessment of cogeneration and trigeneration systems for small scale applications. Energy Convers. Manag. 2016, 125, 194-208. [CrossRef]

31. Jarimi, H.; Powell, R.; Riffat, S. Review of sustainable methods for atmospheric water harvesting. Int. J. Low-Carbon Technol. 2020, 15, 253-276. [CrossRef]

32. Gordeeva, L.G.; Solovyeva, M.V.; Sapienza, A.; Aristov, Y.I. Potable water extraction from the atmosphere: Potential of MOFs. Renew. Energy 2020, 148, 72-80. [CrossRef]

33. Milani, D.; Abbas, A.; Vassallo, A.; Chiesa, M.; Al Bakri, D. Evaluation of using thermoelectric coolers in a dehumidification system to generate freshwater from ambient air. Chem. Eng. Sci. 2011, 66, 2491-2501. [CrossRef] 
34. Fathieh, F.; Kalmutzki, M.J.; Kapustin, E.A.; Waller, P.J.; Yang, J.; Yaghi, O.M. Practical water production from desert air. Sci. Adv. 2018, 4, eaat3198. [CrossRef] [PubMed]

35. He, W.; Yu, P.; Hu, Z.; Lv, S.; Qin, M.; Yu, C. Experimental Study and Performance Analysis of a Portable Atmospheric Water Generator. Energies 2019, 13, 73. [CrossRef]

36. Moghimi, F.; Ghoddusi, H.; Asiabanpour, B.; Behroozikhah, M. Is atmospheric water generation an economically viable solution? Clean Technol. Environ. Policy 2021, 23, 1045-1062. [CrossRef]

37. Atmospheric Water Generator or Water-from-Air Machine Suppliers Links. Available online: http://www.atmoswater.com/ manufacturers-and-suppliers-of-atmospheric-water-generators--water-from-air-machines.html (accessed on 5 January 2021).

38. Genco, A.; Viggiano, A.; Viscido, L.; Sellitto, G.; Magi, V. Numerical Simulation of Energy Systems to Control Environment Microclimate. Int. J. Heat Technol. 2016, 34, S545-S552. [CrossRef]

39. Hitchin, R. Primary Energy Factors and the primary energy intensity of delivered energy: An overview of possible calculation conventions. Build. Serv. Eng. Res. Technol. 2019, 40, 198-219. [CrossRef]

40. EN ISO 5200-1: 2017. Energy Performance of Buildings-Overarching EPB assessment_Part 1: General Framework and Procedures; International Organization of Standardization: Geneva, Switzerland, 2017.

41. EN 12831-3:2017. Energy Performance of Buildings_-Method for Calculation of the Design Heat Load—Part 3: Domestic Hot Water Systems Heat Load and Characterisation of Needs, Module M8-2, M8-3; European Committee for Standardization: Brussels, Belgium, 2017.

42. IEA. Available online: https://www.iea.org/countries/mexico (accessed on 4 February 2021). 